\title{
Benito Milla: un Ulises desgraciado en el Río de la Plata. De Cuadernos Internacionales a Mundo Nuevo, del socialismo libertario al humanismo antibelicista
}

\section{Benito Milla: a Ulises desgraciado in the Río de la Plata. From Cuadernos Internacionales to Mundo Nuevo, from Libertarian Socialism to Antiwar Humanism}

\begin{abstract}
Resumen
El siguiente artículo se propone recuperar la gestión cultural del republicano español exiliado en Montevideo Benito Milla entre los años 1950 y 1965. Desde su arribo a Montevideo, alentado por sus ideales anarquistas, Milla configura un espacio de referencia para la cultura uruguaya que va reconfigurando una izquierda humanista y antibelicista. A través de sus revistas Cuadernos Internacionales, Deslinde, Letras 62, Número (2a. época) y Temas, pero también a través de las editoriales que crea para la difusión de los nuevos talentos de la Generación del 45: Deslinde y Alfa, se constituye en un eslabón fundamental para comprender la fuerte expansión de la cultura uruguaya en esos años.
\end{abstract}

Palabras claves Literatura, Revistas Uruguayas, Cultura anarquista, Generación del 45

\begin{abstract}
The following article aims to recover the cultural management of the Spanish republican exiled in Montevideo Benito Milla between the 1950s and 1965s. Since his arrival in Montevideo, encouraged by his anarchist ideals, Milla sets up a reference space for the Uruguayan culture that is reconfiguring a humanist and anti-war left wing. Through its magazines Cuadernos Internacionales, Deslinde, Letras 62, Número ( $2^{\text {nd }}$ ep.) and Temas, but also through the editorials that he creates for the diffusion of the new talents of the Generation
\end{abstract}


of 45: Deslinde and Alfa, Milla constitutes himself in a fundamental link to understand the strong expansion of Uruguayan culture in those years.

Keywords Literature, Uruguayan Magazines, Anarchist Culture, Generation of 45

La sociabilidad del Montevideo de fines de los '50, se consolidó en torno a varios proyectos impulsados por la luego reconocida Generación del '45 o Generación Crítica, llamada así por Emir Rodríguez Monegal y Ángel Rama, respectivamente. Como reconstruye Ximena Espeche, esta generación impulsó iniciativas culturales exitosas de gran resonancia, entre ellas fueron significativos los proyectos editoriales y la producción revisteril con títulos nodales en la cultura uruguaya de aquellos años como Clinamen, Escritura, Número, Asir o Entregas de la Licorne, donde los "colaboradores tendían a repetirse, con escasas variantes, ya que los intelectuales de esta generación circularon por casi los mismos espacios" (133-137). Hasta mediados de los '50, a excepción de las ediciones de Número, proliferaron los proyectos revisteriles debido a que las editoriales, "cuya ausencia es una vergüenza para todo el país" (Rama, "Generación” 52-53), no habían florecido como lo hicieron luego.

En particular la revista Número, "órgano oficial de la generación del '45" (Conteris, "Entrevista” 183-186) agrupó intelectuales que una década más tarde se verían enfrentados y arrastrados por el ciclón de la guerra fría latinoamericana. ${ }^{1}$ Fundada por Idea Vilariño, Manuel Claps y Emir Rodríguez Monegal, sumó a partir de su octava entrega a Mario Benedetti. Número nacía de la confrontación en otra revista previa, Clinamen ${ }^{2}$ - cuyo jefe de redacción era Ángel Rama - y apareció en dos épocas, entre 1949 y 1964, con un intermezzo de siete años entre ellas ${ }^{3}$. En este

${ }^{1}$ En sus páginas colaboran entre otros: Mario Arregui, Juan Cunha, Pedro Salinas, Ezequiel Martínez Estrada, Guillermo de Torre, Albert Camus y Carlos Martínez Moreno.

${ }^{2}$ Clinamen. Revista bimestral. $\mathrm{n}^{\circ} 1$ (marzo-abril 1947) - $\mathrm{n}^{\circ} 5$ (mayo-junio 1948). Editada por los estudiantes de la Facultad de Humanidades y Ciencias (UDELAR). Su Consejo de dirección estuvo constituido por Víctor J. Bacchetta, Manuel A. Claps, Ida Vitale y Ángel A. Rama, que también fue su jefe de redacción. Colaboraron en sus páginas entre otros Emir Rodríguez Monegal, Carlos Rama, Mario Arregui y Juan Cunha.

${ }^{3}$ Número, 1a. época: $\mathrm{n}^{\circ} 1$ (marzo 1949) - $\mathrm{n}^{\circ} 27$ (diciembre 1955); 2a. época: $\mathrm{n}^{\circ} 1$ (abril 1963) - $\mathrm{n}^{\circ}$ 3/4 (mayo 1964). 
período, la joven Generación crítica va a colaborar en varios emprendimientos. Menos conocidas, pero fundamentales por el eslabón que significan en la trayectoria de esta red, las revistas Deslinde 4 y Letras $62^{5}$, ambas del exiliado republicano y anarquista Benito Milla, van a reunir algunas de las plumas de los editores y colaboradores de Número entre su primera y su segunda época.

Aunque voy a referir explícitamente a Uruguay, los hechos ocurridos en esta brecha entre 1955 y 1963 serían determinantes para la reestructuración del campo intelectual latinoamericano, un período en el que, como señala Claudia Gilman, se produjeron rupturas que reconfiguraron "las tramas de la intensa sociabilidad letrada" ("Enredos” 69-92). El más importante, por supuesto, fue la Revolución cubana, que marcó un antes y un después polarizando el mundo de la cultura. Sin embargo, la transformación del mapa intelectual estuvo asimismo jalonado por otros hechos, incluso previos al '59, que produjeron diferentes tensiones, como la emergencia de quienes serían los dos críticos más importantes del período - forjados en las entrañas del semanario Marcha - Emir Rodríguez Monegal y Ángel Rama; el ascenso del escritor Mario Benedetti, muy pronto compañero de ruta de la Revolución cubana; o la llegada a Montevideo de un gestor clave de la cultura latinoamericana como Benito Milla, fundador de otra de las editoriales estrella del período, Alfa, editor de la segunda época de Número, director del Centro Uruguayo de Promoción Cultural vinculado al Instituto Latinoamericano de Relaciones Internacionales (ILARI) y de la revista Temas (antecedente de la reconocida Mundo Nuevo), creador y director en los sesenta de las editoriales venezolanas Monte Ávila y Tiempo Nuevo, y luego de la española Laia (1970).

Los dos primeros nombres, Rama y Rodríguez Monegal, serán protagonistas indiscutidos de la ciudad letrada de esos años y hacedores, cada uno a su modo, del célebre Boom literario junto a su contraparte cubana reunida en Casa de las Américas. De Rodríguez Monegal y Rama se han escrito variados textos y

\footnotetext{
${ }^{4}$ Deslinde, Montevideo, $\mathrm{n}^{\circ} 1$ (agosto 1956) - $\mathrm{n}^{\circ} 16$ (1961).

${ }^{5}$ Letras 62, Montevideo, $\mathrm{n}^{\circ} 1$ (septiembre 1962) - $\mathrm{n}^{\circ} 2$ (diciembre 1962).
} 
reseñas biográficas que dan cuenta de los diferentes recorridos, la influencia que ejercieron en el campo de la cultura y el tipo de intervenciones con las que se convirtieron en personajes públicos. Sin embargo, de Milla la información es escasa. Una excepción la constituye el libro de Alejandra Torres Torres centrada en la experiencia de la editorial Alfa y un artículo propio donde refiero brevemente a su trayectoria a razón de su intervención en la revista Mundo Nuevo (Jannello, "Boom" 115-133). Se hace necesario, entonces, relevar algunos aspectos de la vida de este gestor cultural para comprender la relevancia que tuvo su intervención en el campo cultural latinoamericano y reponer sobre todo un eslabón clave que estimuló de algún modo la emergencia de autores que hoy forman parte del canon literario de la región.

\section{Un "Ulises desgraciado" ${ }^{6}$ encuentra el rumbo.}

Nacido en Villena, Alicante, en $1918^{7}$, Benito Milla militó tempranamente en las Juventudes Libertarias de Catalunya y apenas estalló la Guerra Civil se alistó en la célebre Columna Durruti, donde fungió de secretario entre 1936 y 1937. En este período también colabora en el periódico El Frente. Boletín de guerra de la Columna Durruti. En 1938 es nombrado vicesecretario de la Federación Ibérica de Juventudes Libertarias ${ }^{8}$ y toma a su cargo la dirección del periódico Ruta. Portavoz de las Juventudes Libertarias (Barcelona), tarea que continúa más tarde en su exilio en Toulouse9 ${ }^{9}$.

${ }^{6}$ Tomado de la descripción que hace de sí el mismo Milla en el único cuento que he podido registrar por él publicado, titulado "La ciudad de los otros", publicado en 1960 en Deslinde n. 14/15.

${ }^{7}$ Las diferentes reseñas biográficas no se ponen de acuerdo con esta fecha, pero Benito Milla declara en una entrevista que nació en 1918. Cfr.: Milla, Benito, "La nueva promoción de lectores". Mundo Nuevo. $\mathrm{N}^{\circ} 19,1$ ene. 1968: 83-87.

${ }^{8}$ Cfr.: "El Pleno de las Juventudes Libertarias". Solidaridad Obrera. 21 jun. 1938: 7.

9 Según registra Antonio Téllez-Solá, Benito Milla dirigió Ruta en el exilio desde su número 9 (19/7/1945). Cfr.: Téllez-Solá, Antonio. "Sobre Ruta, CNT y Soli”. Historia libertaria. N 6, dic. 1979: 39-40. 
El 21 de abril de 1949 llega a Buenos Aires en el buque Florida proveniente de Marsella junto a su amigo el escritor anarquista José Carmona Blanco (1926$2004)^{10}$, quien lo acompañará en el periplo del exilio y en los primeros proyectos latinoamericanos. En Buenos Aires, los dos amigos toman contacto con Solidaridad Anarquista Internacional, donde se crea a poco de su arribo (quizás a instancia de ellos mismos) la Subdelegación del Movimiento Libertario Español en el exilio y el Movimiento CNT Española en Argentina, dependiente de la Comisión Intercontinental del Movimiento CNT Español Exiliado de Francia. ${ }^{11}$ Sin embargo, contrariados por lo que representaba el gobierno de Perón (definido como una "dictadura legal"12), estos republicanos en poco tiempo se trasladan a Uruguay. ${ }^{13}$

\section{Milicias quijotescas}

En 1951, Benito Milla se encuentra instalado con un puesto de libros en la Plaza Libertad de Montevideo, lugar de reunión de los escritores de la generación del '45, donde conoce a Emir Rodríguez Monegal y a Mario Benedetti, entre otros. Sus primeros vínculos en la capital uruguaya son también con los grupos

${ }^{10}$ Según los registros del Centro de Estudios Migratorios Latinoamericanos Benito Milla Navarro declaró a su arribo tener 30 años -aunque sabemos que era mayor -, estar casado, ser católico y de profesión zapatero. Carmona Blanco era menor, contaba al momento del arribo con 23 años, y su profesión declarada fue "contabile". Milla y Carmona Blanco se habían conocido en Catalunya, en los años de la Guerra Civil, cuando el primero participaba en la famosa Columna Durruti y el segundo era comisario en la Brigada 226.

${ }^{11}$ Varios artículos publicados en el periódico La Protesta de Buenos Aires permiten inferir este momento en la vida de Benito Milla y Carmona Blanco: "A los exiliados españoles en Argentina", "Para derrocar a Franco", "A los exiliados libertarios españoles en Argentina" y "A los exiliados libertarios españoles", en n 7984,1 may. 1949: 11 y 14; $\mathrm{n}^{\circ}$ 7985, jun. 1949: 4; y n 7987, sept. 1949: 2, respectivamente.

${ }^{12}$ De este modo sería percibido el gobierno de Juan D. Perón apenas poco tiempo después. Cfr.: Cruz Arjona, C. "El falso dilema EEUU o Rusia". Cuadernos Internacionales. $\mathrm{N}^{\circ} 3$, jul.-sept. 1951: 163-166.

${ }^{13}$ Como señala Dora Schwarzstein, se trató de una experiencia compleja para los exiliados debido a que encontraban entre el peronismo y el franquismo afinidades ideológicas muy marcadas. Cfr.: "La conformación de la comunidad del exilio republicano en la Argentina". Hebe Clementi (coord.). Inmigración española en la Argentina (Seminario 1990). Buenos Aires: Oficina cultural de la Embajada de España,1991: 221-231. 
anarquistas locales. Su experiencia militante y editora precipitan el primer emprendimiento junto a Carmona Blanco: Cuadernos Internacionales ${ }^{14}$, que pretendía hacer una contribución a una "nueva valorización del anarquismo" ("Propósito" 3-4). En sus páginas publican entre otros a Albert Camus, Herbert Read, Michel Crozier, Eugen Relgis, José García Pradas o José Peirats; y reseñan ensayos de Ernesto Sábato, George Orwell, Bertrand Russell, John Dos Passos, Josué de Castro, Rudolf Rocker, Max Nettlau o George Woodcock, entre otros. Milla tiene además el don de la palabra y una vasta producción, escribe artículos políticos o reseñas, traduce o corrige, lee y hace crítica literaria y/o teatral ${ }^{15}$. Por otra parte, colaboran también en el emprendimiento algunos autores uruguayos como el sociólogo Carlos Rama o el poeta Emilio Ucar, de la generación del '45, o el joven jefe de redacción Ernesto Maya (h), a quienes podremos ver en poco tiempo junto a Milla y Carmona Blanco compartiendo proyectos a venir.

Cuadernos Internacionales es una publicación cultural claramente militante, que advierte sobre los desengaños de la revolución ("La idea de 'la revolución', que tal imperio ha ejercido durante más de un siglo y medio, muere ahora, precisamente porque los revolucionarios dejan - o dejamos - de creer en ella"16), que postula el universalismo y el colectivismo - un orden social que aspirando a recuperar un cierto socialismo libertario, pone en el corazón de su sistema la libertad individual, porque "de cada uno según sus medios, y a cada uno según sus necesidades” (Maline 93-97) -, así como el derecho a una “justicia social

\footnotetext{
${ }^{14}$ Cuadernos Internacionales, Montevideo, $\mathrm{n}^{\mathrm{o}} 1$ (enero-marzo 1951) - $\mathrm{n}^{\mathrm{o}} 4$ (octubre 1952).

${ }^{15} \mathrm{Su}$ actividad como gestor cultural y editor van a ir recortando sus tiempos de escritor, aunque su entusiasmo, por lo menos hasta fines de los 60 es evidente. En una carta que dirige a Ramón Sender, del 7 de octubre de 1959, le señala respecto a un texto que escribe sobre él que "mi artículo sobre Vd. se quedó a la mitad de lo que importaba decir [...] Pienso completarlo [...] para incluirlo en una serie de ensayos sobre la novelística contemporánea". El artículo al que refiere salió publicado en Deslinde ${ }^{\circ}$ 12, sept. 1959: 8-9.

${ }^{16}$ La reflexión pertenece al anarquista José García Pradas que critica el socialismo real de la Unión Soviética, convertido en "el modelo" de revolución, pero no renuncia a la utopía de un sistema socialista libertario. Cfr.: García Pradas, José. "El concepto de la revolución y sus contrasentidos". Cuadernos Internacionales. №3, jul.-sept. 1951: 120-137.
} 
para todos”, con una ambiciosa red de contactos que la distribuirán en Brasil, Cuba, Estados Unidos, Francia e Inglaterra. ${ }^{17}$

Como presentación, su primer número abre con un texto de Albert Camus - con quien Milla mantiene a su vez una fluida correspondencia personal - sobre “El destino del individuo", y continúa con un exaltado y kropotkiniano José García Pradas, y una ácida crítica hacia el marxismo soviético que será una constante en sus páginas, así como hacia el "americanismo... pragmatismo idólatra de la fuerza" (Prunier 70-72) y de “psicología autoritaria” (Milla, “Guerra” 90-92).

Ciertamente financiada por el grupo que la promueve (sin anuncios publicitarios de ningún tipo) e ilustrada con xilografías del anarquista español residente en Montevideo Juan Pardo (1893-1969) ${ }^{18}$, con motivos proletarios o campesinos, de formato cuaderno y paginación continua, mantiene una frecuencia cuatrimestral en los primeros tres números, en tanto que una brecha de un año separa el lanzamiento del cuarto, que será el último. Austera en su estilo, CI estará asociada también al universo de los poetas, ya que "Es bien clara la posición: Poetas, Anarquistas y Quijotes, todo uno. Porque los tres llevan el "no me da la gana" contra toda forma de reacción" (Otero 33-37). Preocupación genuina encabalgada en otra mayor: la función de los escritores, de los intelectuales, en la sociedad y su compromiso con las ideas.

Estos anarquistas españoles recién aclimatados en el ambiente rioplatense comprenden rápidamente que en el crudo drama de la Guerra Fría las elecciones son estrechas y ponen en duda la opción planteada por entonces por Bertrand Russell de dar apoyo a los Estados Unidos ante la "existencia del agresivo imperialismo stalinista", la elección del "mal menor"19. Aún cuando todavía las marcas de la intervención comunista en la Guerra Civil están presentes, para estos

${ }^{17}$ Según da cuenta la retiración de contratapa de sus números.

18 Juan Pardo falleció en su exilio en Montevideo. Ilustró además las páginas de las montevideanas Solidaridad y Voluntad.

19 Por esos años, Bertrand Russell era presidente honorario del Congreso por la Libertad de la Cultura, organización atlantista y anticomunista que entre otros tenía por objetivo difundir el american way of life, y que en la década siguiente será juzgada por recibir fondos de la Central de Inteligencia Americana. 
exiliados no es menor el apoyo de la Casa Blanca al régimen franquista; ante una eventual tercera guerra, "con el triunfo norteamericano no todos los que luchen van a ganar lo mismo... un triunfo norteamericano es la perpetuación de Franco en el poder" (Milla, “Guerra” 90-92) ${ }^{20}$. El Montevideo “tercerista” será entonces el lugar que sientan más cercano a sus aspiraciones a una tercera vía. Lo que Estados Unidos promueve es un imperialismo tan peligroso como el de la URSS, aunque entienden que no se trata de la voluntad de su pueblo, sino que hacen responsable a la "voracidad de sus clases directoras" (Ibíd.).

Cuadernos Internacionales alienta el pacifismo siguiendo el pensamiento de Alex Comfort y el anarquismo sin adjetivos de Rudolf Rocker ${ }^{21}$. Coincide con Albert Camus en sus críticas al marxismo en L’homme revolté y critica el extremismo religioso de los intelectuales que desertan de las filas comunistas, lo que se convierte en una crítica al anticomunismo de los conversos como Arthur Koestler.

La publicación es toda ella una toma de posición, un anunciar permanente de sus convicciones, casi un manifiesto de presentación en la sociedad rioplatense. Estos hombres se asumen exiliados a tal punto que cuando traen el problema del imperialismo norteamericano a debate, lo hacen en la sección de "Asuntos Internacionales". Sin embargo, el problema del vínculo latinoamericano con los Estados Unidos está más presente que lo que se percibe a primera vista. América Latina, la región que los recibe, es parte del mundo occidental dominado por el “imperialismo yanqui" y está sometida a la política del "buen vecino" implantada en la Conferencia Panamericana de Bogotá, y esto los hermana con los españoles derrotados, porque

Con esto han quedado las manos libres para estimular las ambiciones militaristas que, como mal endémico, sufre América y que saben que sus

\footnotetext{
${ }^{20}$ Resaltado en el original.

${ }^{21}$ Que fomenta la asociación voluntaria, garantizando por sobre todo la libertad personal y social de los hombres.
} 
CATEDRAL TOMADA: Revista de crítica literaria latinoamericana / Journal of Latin American Literary Criticism Benito Milla: un Ulises desgraciado en el Río de la Plata. De Cuadernos Internacionales a Mundo Nuevo, del socialismo libertario al humanismo antibelicista

golpes de fuerza y cuartelazos reciben inmediata sanción internacional, con solo declarar su anti-comunismo y su amistad a los Estados Unidos. (Cruz Arjona 163-166)

Es esta percepción del peligro que representa la fuerza imperialista que favorece las ambiciones militaristas con solo declararse anticomunista, lo que los conmueve; analogía que no puede ser más evidente con su amada España. Sin justificar al comunismo, que por supuesto es aborrecible, hay intereses más voraces detrás (el imperialismo yanqui) que pretenden aprovechar este odio al comunismo para traer algo peor: "las oprobiosas y negras tiranías" (Ibíd.).

\section{El deslinde}

A pesar de estas apreciaciones conjuntas, la poesía, la cultura y el arte, "último reducto del hombre que escapa a la barbarie" ("Deslinde" 1), serán un capital simbólico que permitirán a Milla durante esos primeros años de librero e insipiente editor, expandirse a otros universos de su interés. Escribe la página literaria del periódico batllista Acción y lleva en paralelo exposiciones plásticas al interior del país, según recuerda el escritor Hugo García Robles (193-198).

Para 1954, con la ayuda del maestro y poeta anarquista coloniense Adolfo Rodríguez Mallarini ${ }^{22}$ da el salto intrépido de establecerse en un local de la calle Ciudadela 1349, que quedará en la memoria de la capital uruguaya como espacio de sociabilidad: allí instala primero la distribuidora Alfa, luego librería y muy pronto editorial.

Existen diferentes versiones respecto al momento de inicio de actividades de la famosa editorial a la que este exiliado español dio origen en Montevideo. $\mathrm{Su}$

\footnotetext{
${ }^{22}$ Hugo García Robles recuerda que el inicio de Alfa se logró con ayuda de "Quian Mallarini”, aunque debe referirse seguramente al maestro y escritor Adolfo Rodríguez Mallarini, laureado por la Academia Nacional de Letras uruguaya en 1948 por un ensayo sobre Cervantes.
} 
nombre aludía al "primer signo", inicial de "acracia"23. Emir Rodríguez Monegal señala como momento de inicio el año 1954 (105-109). Por otra parte, Alejandra Torres Torres indica que el primer libro con sello "Alfa" data de 1959 (95-110), aceptando las declaraciones del propio Milla en una entrevista realizada en 1968 ("Nueva promoción" 83-87), y las del Grupo Editorial Alfa, que sostiene oficialmente que el inicio de sus actividades se registra en $1958^{24}$. Por último, la historiadora Rosa Grillo (219-230) indica que la editorial nace en 1956, mediante un acuerdo de sociedad intelectual de Benito Milla con Ángel Rama, que dirigirá una de las primeras colecciones. Como consecuencia natural de este emprendimiento, según la historiadora, surge una publicación, Deslinde ${ }^{25}$; sin embargo, Ángel Rama no se encuentra en el comité de redacción de la nueva revista, referiré a ella más adelante.

Recorriendo el semanario Marcha de Montevideo podemos comprobar la existencia de Alfa como distribuidora para fines de junio de 1954, sobre todo de editoriales del mundo anarquista argentino. ${ }^{26} \mathrm{Y}$ un par de años más tarde, en agosto de 1956, encontramos el lanzamiento de Deslinde, editada en Librería Alfa. De esta iniciativa surge además un emprendimiento editorial homónimo que saca apenas

${ }^{23} \mathrm{Al}$ ser la primera letra del alfabeto griego antiguo, significa el principio de algo, por oposición a omega, que simboliza el fin. Carlos Maggi hizo una breve referencia al nombre elegido por Milla para su editorial en el fascículo que dirigió para Capítulo Oriental en 1968.

${ }^{24}$ Se puede verificar en la historia del Grupo Alfa, dirigido en la actualidad por el nieto de Benito Milla, Ulises.

${ }^{25}$ Según Hugo García Robles, aunque Ángel Rama buscaba concretar la sociedad en el negocio editorial, no hubo acuerdo porque "Milla, como buen anarquista, era individualista" (Torres Torres, 2012: 196); Rama, luego de dirigir la colección "Letras de hoy" en 1960, se distanció de Alfa e inició su propio emprendimiento con un nombre muy similar y que también tiene significación en el mundo anarquista: Arca. De cuatro letras al igual que Alfa, también comienza con la "A" anarquista, a la vez que las dos primeras letras podrían referir a las iniciales del crítico.

${ }^{26}$ El primer anuncio aparece en Marcha n. 725 (25/6/1954) y ofrece ediciones de Américalee de Buenos Aires. Para fines del mismo año sacan anuncios más importantes como "Distribuidora Alfa. Un servicio de Difusión Cultural para todo el país" y en los años que siguen la oferta se amplía a libros de editoriales libertarias o anarquistas como la Compañía General Fabril (de Jacobo Muchnic, con colecciones dirigidas por el poeta surrealista Aldo Pellegrini), Reconstruir e Imán, entre otras; además de algunas editoriales de izquierda como Transición de Dardo Cúneo o Nova, que editaban textos de marxismo crítico o herético como los de Kautsky. Pronto será también distribuidora de Sur, Paidós y Jorge Álvarez, entre otras. 
CATEDRAL TOMADA: Revista de crítica literaria latinoamericana / Journal of Latin American Literary Criticism Benito Milla: un Ulises desgraciado en el Río de la Plata. De Cuadernos Internacionales a Mundo Nuevo, del socialismo libertario al humanismo antibelicista

algunos títulos del poeta Saúl Ibargoyen $\operatorname{Islas}^{27}$ y uno de Emilio Ucar ${ }^{28}$, ya en paralelo con las actividades editoriales de Alfa.

A pesar de la fecha oficial de su inauguración, en 1957 se reseña también en Marcha, un libro del español Francisco Ferrándiz Alborz, Marimba y otros cuentos bárbaros "editado por Alfa"29; y en 1958 sale Arena del Tiempo, de Alex Pereyra Formoso, asiduo colaborador de Deslinde. Podemos suponer entonces que las actividades editoriales de “'Don Benito', como lo llamaron con afectuoso respeto quienes lo trataron de cerca" (Aínsa, Canon 101-102), no fueron tan lineales. Era bastante habitual por esos años (y sobre todo en mercados pequeños como el uruguayo) que las librerías editaran y se colocaran como sello editorial. Similar al caso de Alfa podemos mencionar el de Librería Atenea. ${ }^{30}$ Teniendo esto en cuenta, las declaraciones de Rodríguez Monegal sobre los inicios de las actividades editoriales de Alfa no serían descabelladas si se considera por ejemplo la edición del libro de Eugen Relgis de 1954, El hombre libre ante la barbarie totalitaria, con pie de imprenta editorial del Ateneo de la Universidad, pero que exhibe además el sello de Alfa como "distribuidora exclusiva”, lo que puede llevar a suponer alguna intervención de Milla en su edición. Otro tanto ocurre con Hombre entre luz y sombra, de Juan Cunha, autofinanciado por el autor, impreso en los Talleres Gráficos Gaceta Comercial a finales de 1955.

${ }^{27}$ Este poeta inicialmente se había autofinanciado sus obras El pájaro en el pantano (1954) y El rostro desnudo (1956); pero a partir de 1958 aparecen con sello Deslinde: El otoño de piedra (1958), Pasión por una sombra (1959), El libro de la sangre (1959) y Un lugar en la tierra (1960). Cuando el emprendimiento de Deslinde ya está concluido, el autor publica Ciudad por editorial Alfa (1961).

${ }^{28}$ En 1960 sale Hoy, cada día.

${ }^{29}$ Cfr.: "Nuevas publicaciones". Marcha, n 893, 20 dic.1957, p. 23.

${ }^{30}$ Como el mercado de lectores era pequeño y las políticas públicas limitadas, las editoriales carecían de recursos para su expansión. Era habitual entonces que los autores autofinanciaran sus obras con el Banco de la República, que daba préstamos personales a los intelectuales para la edición de obras inéditas con un interés del $3 \%$. Para fines de los '50, bajo la iniciativa de Carlos Maggi por esos años abogado del banco - comenzaron a otorgarse créditos más flexibles que el autor podía endosar a la editorial. Cfr.: Maggi, Carlos. "Estrellas en 45". Gabriela Gómez. La Diaria, 11 ene. 2013. Web. 15 jul. 2018 <https//:1a diaria.com.uy/articulo/2013/1/estrellas-en-45/>. Véase además: Benedetti, Mario. "Archivos O’Donnell”. Canal Encuentro. Web 25 jun. 2018 https://www.youtube.com/watch?v=LaMyQ1V43SI 


\section{Los eslabones perdidos}

La primera revista editada por Librería Alfa sale trimestralmente. Su título rinde homenaje a Alfonso Reyes ("Deslinde” 1), y su consejo de redacción está constituido inicialmente por varios anarquistas que participaron en Cuadernos Internacionales: José Carmona Blanco, el poeta Emilio Ucar y el novelista Ernesto Maya (h). Pero este equipo será más amplio, de ambición integradora, y se incorporan además algunos jóvenes uruguayos como el crítico de arte Nelson Di Maggio y el escritor y periodista Hugo García Robles, que inicia su recorrido como crítico ("Colaboradores" 25) y que acompañará a Benito Milla en otros emprendimientos que se sucederán a futuro. ${ }^{31}$

Como señala Rosa Grillo (219-230), la publicación da cuenta del proceso de adaptación de estos amigos exiliados (Milla y Carmona Blanco) en los que "pasados los primeros años de intensa actividad dirigida a la defensa y al mantenimiento de la identidad [española y republicana] surge la necesidad de abrirse cada vez más al mundo latinoamericano", y sus páginas ofrecen una “naciente conciencia latinoamericana" (Aínsa, "Revista” 259-268).

Por otra parte, la desaparición de Número a fines de 1955 deja huérfano a un grupo de escritores jóvenes y estimula a Milla, que ya se encuentra plenamente asentado, a sumergirse en la nueva iniciativa ${ }^{32}$. Su actividad intelectual incluso se

31 Hugo García Robles será secretario de redacción de la revista Temas (a la que referiré más adelante), y acompañará a Milla en su migración a Venezuela, participando en las gestiones de las dos editoriales que el catalán va a dirigir en Caracas: Monte Ávila y Tiempo Nuevo, junto a otros emprendimientos como la Librería Alfar y la Distribuidora de Libros Españoles (DILAE) en la década del 70. Finalmente, lo seguirá en el último periplo de su vida, de regreso a Barcelona, donde va a trabajar también con la editorial Laia, última iniciativa de don Benito.

${ }^{32}$ Milla es completamente consciente de la necesidad de este nuevo emprendimiento y cree que los españoles están impelidos a colaborar en la tarea editorial. En una carta a Ramón Sender de comienzos de 1960 le señala que "Comparto su criterio en relación a nuestra tarea en América y también creo que nuestra partida en masa dejaría aquí un vacío difícil de colmar. En Buenos Aires, como en México, la edición, el periodismo y las universidades están llenas de españoles exiliados y su marcha sería una catástrofe para esas actividades. Aquí, en Montevideo, en este momento no hay más revista literaria que Deslinde ni más editor literario que yo...". Cfr.: Carta de Benito Milla a Ramón Sender (29/02/1960). En Martínez García, Ana, “Cartas desde Uruguay: Ramón J. Sender y la difusión de su obra en los poyectos editoriales de Benito Milla”. Alazet, 22, n. 19, 2010, pp. 209-223. 
ha intensificado: colabora en el periódico batllista Acción y el local de la calle Ciudadela se ha convertido en cita ineludible para encontrar las novedades editoriales y debatir. Es un momento de necesaria expansión. Como señala César Fernández Moreno:

Tanto el creador como el receptor de la cultura necesitan, alternativamente, concentrarse y dispersarse [...] profundizar en el sentido de su personalidad y también ampliarse en el sentido de la sociedad o de otras personalidades que los rodean [...] La revista es vida social del espíritu [...] escribirla es un acto social en que la individualidad debe [...] dejarse moldear por las exigencias ambientes [...]. (Fernández Moreno 7)

Para el escritor y crítico argentino, una revista “es órgano de expresión de un grupo de personas vinculadas por todos los elementos comunes que supone una generación: edad, elementos formativos, acontecimientos históricos, influencias..." Y esto es Deslinde, que cobija a un sector de jóvenes de la Generación del '45 como el crítico de cine Hugo Rocha, los ya mencionados Emilio Ucar, Mario Benedetti o los hermanos Ángel y Carlos Rama. Pero también exhibe nombres de la aristocracia intelectual (Williams 148-169) como los de Albert Camus, Herbert Read, Juan Goytisolo, Ezequiel Martínez Estrada, Octavio Paz, Alex Comfort, Juan Carlos Onetti o Juan Cunha. Las redes de Benito Milla también se extienden a la otra orilla del Plata y un porcentaje de los colaboradores son porteños: el crítico teatral Francisco Mazza Leiva; los poetas Luis Franco, Raúl Gustavo Aguirre y Basilia Papastamatiú; el crítico literario Guillermo de Torre; el escritor Ernesto Sábato; además del ya mencionado Martínez Estrada.

A diferencia de Cuadernos Internacionales, que hizo una fuerte crítica al comunismo, pero también a los modos del anticomunismo, Deslinde no solo no será una revista anclada en la cultura anarquista, sino que va a dar lugar a algunos “compañeros de ruta" como el poeta Juan Cunha, director de la Gaceta de 
Cultura $^{33}$; la actriz y dramaturga Margarita Xirgú, el director del Teatro del Pueblo, Manuel Domínguez Santamaría; e incluso a comunistas declarados como el dramaturgo Atahualpa del Cioppo, el narrador uruguayo Mario Arregui o el escritor español Armando López Salinas. Realizada por el “empeño de hombres jóvenes [que] pretenden [...] una definición a la vez que una responsabilidad; un puesto de lucha a la vez que un compromiso [...]" ("Han dicho" 18), la crítica política, siempre en el marco de la cultura, no estará ausente; se descubre a través del prisma de la crítica literaria, como aquella que hace el propio Milla a las percepciones de la filósofa Simone de Beauvoir en El pensamiento político de la derecha, porque la autora analiza "en función del método crítico marxista [...] dando por sentado que el marxismo es representativo de la 'izquierda", lo que deja afuera otras opciones como el anarquismo: "Simone de Beauvoir se mueve [...] como si todo el proletariado fuera marxista" ("Intelectuales" 18).

La percepción sobre los sentidos de "izquierda" y "derecha” estará presente también en el convulsionado 1959 latinoamericano en la voz del filósofo Leopoldo Zea (1, 4-6) que define en su "Fenomenología de la derecha", a esta como un sector de la humanidad custodio del statu quo (con pretensiones de universalidad y eternidad), y a la izquierda como su opuesto (la sinistra = lo siniestro, en tanto es ajena al orden preestablecido y negadora de esas pretensiones). Y aunque Deslinde no se pronunciará (como sí lo hicieron otras revistas de la época) sobre la Revolución cubana, intervenciones como esta de Zea dejarán en claro cierto posicionamiento: "Los pueblos o individuos que en nombre de la libertad tratan de limitar la libertad de hombres o pueblos que se consideran con libertad para decidir destinos que le son ajenos son vistos como pueblos e individuos totalitarios. Los pueblos que reclaman para sí el mismo respeto a su soberanía que otros pueblos más fuertes exigen para la suya, son vistos como pueblos al borde de todas las negaciones [...] La dualidad bueno-malo sigue funcionando y justificando moralmente la acción de los representantes de lo bueno" (Ibíd.).

${ }^{33}$ Señala Gerardo Leibner (255) que la Gaceta era "ámbito de expresión y elaboración para los intelectuales comunistas". 
Editada por Alfa, Deslinde se sostiene con algunos anuncios publicitarios, la mayoría del mundo del libro y las editoriales (en muchos casos libros que se venden habitualmente en la librería de Milla y editoriales que esta distribuye). También aparecen algunas librerías montevideanas como Atenea, La Bolsa de los Libros o Anteo. En su redacción (situada en el local de la calle Ciudadela) se realizan encuentros que van a perdurar como un habitus intelectual en la librería del editor anarquista por años ${ }^{34}$. Las reuniones, visitas y eventualmente alguna muestra de artes plásticas ${ }^{35}$ son comentados en las páginas de la revista ${ }^{36}$, lo que da cuenta del entramado de sociabilidad que promueve y las ambiciones de expansión a un mundo cultural más amplio.

A lo largo de sus 16 números y 20 páginas promedio, Deslinde hará un aporte fundamental en esos años a la difusión del teatro independiente - sección generalmente a cargo de José Carmona Blanco - brindando un exhaustivo panorama de obras del Teatro del Pueblo y de El Galpón - dos espacios de la cultura comunista - o La Comedia Nacional, entre otros lugares. Asimismo promueve una encuesta a diferentes exponentes de la dramaturgia donde participan Alberto Candeau, Manuel Domínguez Santamaría, Margarita Xirgú, Eduardo Malet, Enrique Guarnero, Atahualpa del Cioppo o José Estruch, entre otros.

La poesía responde para su director, poeta él mismo ${ }^{37}$, “a una densa experiencia humana captada con retina inefable” (Milla, [Prólogo] 7), por ello, la sección de poesía de Deslinde será también fundamental. Llevada por el poeta Emilio Ucar, encargado de la selección y las reseñas, se destaca la poesía rioplatense, con nombres reconocidos en Montevideo como los de Saúl Ibargoyen Islas, Emilio Oribe, Luis Franco o Juan Cunha, pero también las jóvenes promesas:

\footnotetext{
${ }^{34}$ En la librería "tenían lugar pequeñas tertulias o encuentros que convocaban a Emir Rodríguez Monegal, a Ángel Rama [...] Milton Schinca, Carlos Martínez Moreno” y hasta a el expresidente Luis Batlle Berres. (García Robles 193-198)

${ }^{35}$ Cfr.: "Deslinde expone: Pinturas de Agustín Alamán”. Deslinde, n 7, sept. 1957, p. 2.

36 Cfr.: García Robles, Hugo. “Artistas uruguayos en nuestra Redacción. El guitarrista Carlos Pedemonte". Deslinde, n 10/11, mar. 1959, p. 25; "Jorge de Oteiza" y "José Isaacson en Deslinde". Deslinde, n $14 / 15$, oct. 1960, p. 8 y p. 20 respectivamente.

${ }^{37}$ Hugo García Robles (193-198) poseía un libro de poemas inédito que Milla le había dado titulado La niebla 1939-1979.
} 
Mario Benedetti, Idea Vilariño, Basilia Papastamatiú, Daniel Giribaldi, Ramiro de Casasbellas, Rodolfo Alonso, Generoso Medina, Leonardo Milla y el mismo Ucar. Asimismo, la poesía internacional tiene reservado un lugar en los nombres de Octavio Paz, Juan Ramón Jiménez, René Char, Monique Benarroyo o Antonio Muñoz. Tan importante será el género para esta publicación que su primer número arranca con la reseña a cargo de Ucar de dos libros de poesía (de Cunha y de Benedetti) en su primera página, pegado a la presentación de la revista. ${ }^{38}$ Será una poesía de temas cotidianos, humanistas, y sobre todo sociales o de expresión ideológica, como lo manifiesta "Liberación" de Antonio Muñoz y la nota de Octavio Paz "La poesía y las masas" 39 , prácticamente un manifiesto al que sin duda Milla circunscribía. Así como en Cuadernos Internacionales se recogía a León Felipe, Deslinde va a tomar la voz de Machado, de García Lorca, de Miguel Hernández; pero también de los latinoamericanos (de pensamiento libertario) Octavio Paz y Luis Franco.

En una proporción similar, las páginas de la revista prestan atención a la música, sección a cargo de Hugo García Robles, y a las artes plásticas (con mayor preeminencia de esta) a partir de la cuarta entrega a cargo de un joven Nelson Di Maggio, quien comenta las exposiciones en Montevideo del Salón de Artes Plásticas, los Salones de la Comisión Nacional de Bellas Artes y la Galería Moretti, y hace un recorrido por la situación del arte a nivel internacional revisando las vanguardias (arte abstracto, suprematismo, etc.).

El arte también está presente en un artículo de Herbert Read incluido en Deslinde 1 (“Arte y abstracción”) y en la promoción de la que parece ser la primera exposición realizada en Librería Alfa, de otro español exiliado en Montevideo, Agustín Alamán. La secuencia estará en línea con lo que afirma uno de los pocos editoriales de Deslinde: "Estamos nutriéndonos de la cultura europea y no tenemos una tradición propia para apuntalar la expresión del arte [...]”. ("Realidad”2)

\footnotetext{
${ }^{38}$ El artículo, de Emilio Ucar, llevó el título de "Notas sobre poesía uruguaya".

39 Ambos en el primer número de Deslinde.
} 
No es hasta los últimos números que Deslinde toma la pintura argentina, quizás porque sus artistas "superan los estrechos límites locales”, donde traza el recorrido de las nuevas corrientes estéticas: Movimiento de Arte Concreto, Asociación de Arte Concreto Invención, Arte Madí, Perceptismo y Grupo de Artistas Modernos de la Argentina. Los nombres que se instalan: los hermanos Lozza, Aldo Pellegrini, Edgard Bayley, Tomás Maldonado, Sara Grilo, entre otros. Y el cruce con la vanguardia poética explicitada en sus publicaciones: Arturo, Arte Concreto Invención, Perceptismo, Arte Madí, Nueva Visión, Ver y Estimar (dirigida por el reconocido crítico Jorge Romero Brest $)^{40}$. La pintura uruguaya merece solo un trabajo, en la penúltima entrega, donde Di Maggio rescata la "Actividad plástica de Montevideo" (7), rescatando la obra de Joaquín Torres García, Manuel Lima, Lincoln Presno, Luis Camnitzer, el joven Hermenegildo Sábat, Hugo Nantes, Hilda López, Héctor Gandos y Tola Invernizzi. Estamos en octubre 1960, es decir que ya se había llevado a cabo la primera Feria del Libro y el Grabado (en la que Milla también colabora) y los jóvenes artistas uruguayos volvían de la quinta edición de la Bienal de San Pablo donde habían logrado darle visibilidad a su obra. ${ }^{41}$

La relación de fuerzas América-Europa se hace más equilibrada cuando se trata de narrativa, donde el porcentaje de los autores rioplatenses se equipara en producciones con las de los extranjeros (la mayoría españoles, muchos de ellos que viven en Montevideo). Una gran parte de los cuentistas rioplatenses son jóvenes promesas, anticipo de la tarea que va a llevar adelante la editorial Alfa, mientras que los españoles son sobre todo autores ya consagrados. Se publican un total de 18 cuentos en las 14 entregas, entre las que se destaca un cuento de Ángel Rama ("Accidente" 10-13) con pinceladas existencialistas, nunca publicado en sus compilaciones narrativas, y dos de las historias que integrarán el exitoso

${ }^{40}$ Cfr.: Di Maggio, Nelson, "Pintura argentina de validez". Deslinde, n 12, p. 20; y “Ocho pintores argentinos". Deslinde, ${ }^{\circ} 13$, pp. 16, 15.

${ }^{41}$ Resulta extraño que Deslinde tomara la pintura uruguaya tan brevemente y solo después de su legitimación internacional. El Taller de Joaquín Torres García tenía construido un nombre para esa época y era reivindicado ya a fines de la década anterior en Clinamen. Cfr.: Rama, Ángel. "Generación va y generación viene". Clinamen, $\mathrm{n}^{\circ}$ 5, may-jun. 1948, pp. 52-53. 
Montevideanos de Mario Benedetti, que "ha recibido un gran despliegue de la crítica" , editado por Alfa en 1959.

Si en Cuadernos Internacionales la producción de textos de Benito Milla era importante, aquí se duplica. Escribe en todos los números entre dos y tres textos: artículos, traducciones del francés y múltiples reseñas. El anhelo por su querida España no ceja en ningún momento, quizás es, de los dos amigos que arribaron a Montevideo, quien más se resiste a dejar atrás su pasado español, y aunque se sobrepone y se adapta a su nuevo país, la prosa es siempre nostálgica de una sociedad que ya nunca volverá a encontrar, ni siquiera cuando regrese a Barcelona, después del largo periplo sudamericano, para crear el último de sus proyectos editoriales: Laia; esta vez en la tierra que lo vio nacer. Esa nostalgia lo lleva a seguir de cerca la cultura de la península y las nuevas promociones de escritores, entre los que se encuentra Juan Goytisolo, de "precoz madurez". El editor catalán es consciente de esa añoranza y es por eso que la crítica a la novela Las afueras es elogiosa, pues sus personajes, que mantienen la "herida abierta" de la Guerra Civil, "se asoman a su pasado y lo ven con alegría, pero remoto e irrecuperable" (Milla "Sobre" 4-5).

Es significativo e interesante además el giro ideológico de Benito Milla por estos años. De pluma militante del anarquismo en $C I$, se dirige, como bien señaló el escritor Fernando Aínsa, hacia un "humanismo antibelicista y siempre antifranquista" (Aínsa, "Revista" 259-268). Las marcas de este desplazamiento pueden percibirse a lo largo no solo de sus textos, sino también de aquello que decide incluir en las páginas primero de Deslinde, luego en Letras 62 y por último en Temas. Su reseña al libro Los fundadores franceses de la sociología contemporánea: Saint-Simon y Proudhon de Georges Gurvitch es sintomática; Milla rescata allí las conclusiones del autor: Proudhon y Marx, más que excluirse se complementan. Aunque esto podría ser posible solo en la teoría y no aplicable al mundo real dominado por un marxismo hegemonizado por los soviéticos, que ha convertido a Marx en "el profeta del autoritarismo". En las mismas páginas reseña

${ }^{42}$ Carta de B. Milla a R. Sender, 29 feb.1960. (ctd. en Martínez García 209-223) 
Los mandarines de Simone de Beauvoir con una dura crítica de tintes moralistas: si el relato de la situación de los intelectuales franceses en la posguerra resulta atractivo - sobre todo por los debates que involucran a los personajes Enrique Perron (Camus) y Roberto Dubreuilh (Sartre) -, el aspecto autobiográfico de las relaciones amorosas de la protagonista, Ana (Beauvoir), deviene en una "insípida historia de amoríos procaces con caída hacia la novela rosa". Reseña también Perspectivas culturales en Sudamérica de Eugene Relgis, del que destaca el desarrollo del "humanitarismo integral" (con el que Milla coincide plenamente) y una compilación de textos de su admirado amigo Albert Camus. ${ }^{43}$

Deslinde anima a la relectura del marxismo y a una concepción humanista porque entiende que

[...] aunque en este momento el anarquismo mundial como fuerza militante no tiene un peso real y cierto, capaz de influir en la consecución de mejores condiciones de autodeterminación para el hombre y la sociedad, está, en cambio, como ideología, llevando a un primer plano en el concierto de los pensadores contemporáneos sus soluciones para crear un equilibrio real [...]. (Maya (h) 11-12)

De este modo puede comprenderse el movimiento de Cuadernos Internacionales a Deslinde, del anarquismo al humanismo libertario del que nos habla Aínsa, donde no faltan los diálogos con el neomarxismo. Puede pensarse que la publicación participa en el plano de las ideas del proceso de integración que el sindicalismo anarquista uruguayo va a promover en esos mismos años con las otras fuerzas de la izquierda ${ }^{44}$, lo que explicaría a su vez que sobre los últimos números el catalán traduzca las "Tesis sobre Marx" del filósofo greco-francés Kostas

${ }^{43}$ Cfr.: en Deslinde n 9 los artículos "Proudhon explicado", "Los Mandarines", "Con optimismo" [y] "Camus cronista".

${ }^{44}$ Véase el testimonio de un protagonista de ese proceso: Trías, Ivonne. Hugo Cores: pasión y rebeldía de la izquierda uruguaya. Montevideo: Trilce, 2008. 
Axelos, de quien años más tarde publicará -ya en la aventura venezolana de Monte Ávila - su célebre Pensamiento planetario.

Deslinde se extingue en junio de 1961, cuando el ciclón caribeño está tronando y la nueva izquierda está brotando en la región. El compromiso intelectual se renueva y se actualiza en sus códigos, pero de esto dará cuenta la tercera empresa revisteril de Milla: Letras 62. Publicación bimestral de artes y letras.

La nueva empresa, breve, de tan solo dos ejemplares, de formato similar a Deslinde - casi no hay diferencias en el formato -, está integrada prácticamente por el mismo grupo, solo percibimos la ausencia de José Carmona Blanco, y la inclusión de nuevos integrantes de la Generación del 45, como Carlos Martínez Moreno $^{45}$ o Carlos Brandy.

Mario Benedetti tendrá un protagonismo estelar gracias a la visibilidad y éxito que había logrado en los últimos cuatro años ${ }^{46}$ y por ser "dentro de la fauna local, uno de los tipos más interesantes e inteligentes" ${ }^{" 47}$. Letras 62 le publica tres textos de los que se destaca "La literatura como catapulta", que abre el segundo número $^{48}$, por tratarse de una reflexión crítica sobre el compromiso intelectual donde el poeta uruguayo defiende la autonomía del pensador frente a la política sin dejar de reclamar la vinculación del escritor con su época porque

Una cosa es que el escritor decida pronunciarse y comprometerse frente a un hecho político determinado, y otra, que brinde en su obra...un apoyo a

\footnotetext{
${ }^{45}$ Pocos años más tarde director junto a Carlos Maggi y Carlos Real de Azua de Capítulo Oriental, historia de la literatura uruguaya, del Centro Editor de América Latina.

${ }^{46}$ Además de su consagración en el semanario Marcha, Benedetti había sacado ya con Alfa cuatro libros: Montevideanos (1959), que llevaba para 1962 su segunda edición y que "ha sido recibido con un gran despliegue de crítica" [Carta de B. Milla a R. Sender 29 feb. 1960, ob. cit.]; La Tregua (1960), agotado en su primer tiraje; Mejor es meneallo (1961), conjunto de crónicas de humor publicadas por Benedetti en Marcha con el seudónimo "Damocles"; y Poemas del hoy por hoy (1961). Pero además había publicado por Asir El país de la cola de paja (1960) que rápidamente alcanzó una difusión inusual para esos años en Montevideo con tres ediciones y un total de 4500 ejemplares vendidos.

${ }^{47}$ Carta de B. Milla a R. Sender, 29 feb. 1960, ob. cit.

${ }^{48}$ No ha sido posible dar con el primer número, aunque sí se ha podido recuperar el sumario de la publicidad en Marcha. En este ejemplar Benedetti publica "Pobres moscas" y "La muerte de William Faulkner" (este último con Carlos Martínez Moreno).
} 
CATEDRAL TOMADA: Revista de crítica literaria latinoamericana / Journal of Latin American Literary Criticism Benito Milla: un Ulises desgraciado en el Río de la Plata. De Cuadernos Internacionales a Mundo Nuevo, del socialismo libertario al humanismo antibelicista

un partido político, ejerciendo en sus libros una visible militancia a favor de una ideología. (Benedetti 1, 4-5)

Son años previos al involucramiento severo de Benedetti con la Revolución cubana. $^{49}$

En línea con este tema, se publica además una breve nota sobre el ganador del Premio Nobel de ese año, John Steinbeck (al que también publican en Deslinde), que defiende que "El pensamiento del hombre ha de ser libre. Y lo será" (3) en su lucha contra los sistemas totalitarios.

El compromiso intelectual para Benito Milla se manifiesta sobre todo en el trabajo destinado a la gestión cultural que se lleva adelante a través de la escritura, pero también de la edición y la promoción del libro y la lectura, dedicando tiempo a entrevistas, mesas de debate y, sobre todo, a la Feria Nacional del Libro (en la que colabora con fervor militante). Letras 62 canaliza la inquietud que ya se percibía en Deslinde sobre la difusión del libro nacional ("por nuestra parte estamos por una promoción directa de nuestras letras" dirá al respecto [“Qué pasa”2]). Concluida la experiencia de la editorial Deslinde, Alfa, "que publica y promueve, de manera profesional, a los autores uruguayos" (Maggi 37) se convertirá en emblema de la cultura, superando muy pronto las fronteras nacionales. En esta línea -anticipándose a lo que luego hará de la polémica revista de Emir Rodríguez Monegal, Mundo Nuevo, un emprendimiento exitoso- la nueva novela latinoamericana asoma ya en la pluma de Carlos Martínez Moreno en una crítica hacia Carlos Fuentes que "aparece preocupado por la técnica de la narración, a la que sabe conducir a alturas desacostumbradas en este continente donde la urgencia

${ }^{49}$ En poco tiempo más comenzará una militancia que lo llevará incluso a vivir en Cuba durante un par de años para crear el Centro de Investigaciones Literarias de Casa de las Américas (1968). A inicios de los '70, ya con el caso Padilla, el escritor hará su elección sobre lo político renegando de su posición previa: "[...] en el trance de elegir entre revolución y literatura, hemos optado por la primera [...]". Cfr.: Paoletti, Mario, El aguafiestas. La biografía de Mario Benedetti. Seix Barral, Buenos Aires, 1995, p. 140. 
de ocupar temas ha desplazado tan radicalmente la de intentar modos narrativos" (Martínez Moreno 8)

Las lecturas neomarxistas se acentúan en Letras 62 como una continuidad en las nuevas lecturas de la Escuela de Francfort, que ya había tenido su lugar en Deslinde en una reseña de Ernesto Maya a Psicoanálisis de la sociedad contemporánea de Erich Fromm. Una larga nota sobre Theodor W. Adorno de Benito Milla reconoce al crítico de la cultura como uno de los pensadores más importantes del siglo XX, con "incisiva penetración de estilo" y "riqueza polémica de ideas" ("Theodor Adorno" 1,3). Para Milla, Adorno nada a contracorriente con una crítica lúcida hacia la cultura y el socialismo real existente.

\section{De Número a Temas, una Revista de la Guerra Fría cultural}

Resulta evidente que la inserción de Benito Milla en el mundo cultural uruguayo ya es un hecho consumado. Durante una década llevó adelante tres proyectos revisteriles y dos editoriales con un saldo muy positivo y se ha granjeado el reconocimiento de la comunidad intelectual convirtiéndose en una "eminence grise dans les milieux littéraires uruguayens" ${ }^{50}$. Particularmente de la generación del '45, de la que se siente cercano por su edad, pero también por intereses comunes.

En 1963 toma la decisión de discontinuar Letras 62 y se suma al proyecto de Número (segunda época), de la que solo será editor (Rocca s/p). Confía en un grupo experimentado con Emir Rodríguez Monegal como jefe de redacción y los nombres de quienes animaran la primera época, y gana un respiro para dedicarse a la pujante editorial Alfa - que ahora comparte el mercado y compite con Arca, fundada por su viejo socio intelectual Ángel Rama, el hermano de este, Germán, y el crítico y ensayista José Pedro Díaz -, y a negociaciones más amplias con el

\footnotetext{
50 Así lo expresaba en correspondencia a John Hunt, Luis Mercier Vega, director Departamento Latinoamericano del Congreso por la Libertad de la Cultura, con quien Milla sostenía conversaciones. MV a JH, 19 dic. 1963. Universidad de Chicago, Fondo IACF, S. II, B. 236.
} 
CATEDRAL TOMADA: Revista de crítica literaria latinoamericana / Journal of Latin American Literary Criticism Benito Milla: un Ulises desgraciado en el Río de la Plata. De Cuadernos Internacionales a Mundo Nuevo, del socialismo libertario al humanismo antibelicista

Congreso por la Libertad de la Cultura (CLC) - una organización atlantista sospechada de financiamiento espurio ${ }^{51}$ - espacio con el que empieza a interactuar en 1962 para llevar adelante "activités d'editeur et de diffuseur sur un plan plus régional" ${ }^{152}$. Y en poco más (1964), reinstala la nueva sede uruguaya del Congreso por la Libertad de la Cultura que llevará por nombre Centro Uruguayo para la promoción Cultural (CUPC). ${ }^{53}$

El renacimiento de Número está, sin lugar a dudas, vinculado al Departamento Latinoamericano del CLC dirigido ahora por el anarquista belgochileno Luis Mercier Vega (Grémion 543-560). Amigo personal de Milla, Mercier lleva un recorrido militante complementario al del editor español, a quien conoce de los años de la Guerra Civil. Su vínculo con América Latina y con el CLC es de larga data, en los años '50 es quien acompaña a Julián Gorkin en la organización de la red de asociaciones en la región, de hecho, mientras Gorkin es la cara pública, Mercier Vega teje las redes que permiten, por ejemplo, la instalación de la primera sede montevideana. En los '60, cuando toma a su cargo la renovación latinoamericana del CLC con la idea de contrarrestar la expansión de la Revolución cubana entre los escritores e intelectuales, organiza en coordinación con el escritor John Hunt ${ }^{54}$ una "chaine de revues" dirigidas a los intelectuales que darían apoyo

\footnotetext{
${ }^{51}$ Las sospechas del financiamiento del CLC, así como sobre sus vínculos con el Departamento de Estado de los EEUU y con la CIA era continuamente denunciado por la izquierda comunista desde el arribo del CLC a la región. En 1966, el periódico New York Times publicará una investigación que Ángel Rama va a replicar en el semanario Marcha, lo que provocó un fuerte escándalo y una animada polémica.

${ }^{52}$ Mercier Vega a John Hunt, op. cit.

${ }^{53} \mathrm{La}$ sede montevideana fue una de las primeras en crearse en América Latina. Estuvo inicialmente a cargo del socialista Emilio Frugoni y luego del exiliado español anarquista Francisco Ferrándiz Alborz. Al fallecer este último en 1961 las actividades de la oficina se estancaron. Aunque el CLC le ofrece a Benito Milla la reactivación de este espacio, él no acepta y vincula a la poetisa Nancy Bacelo, quien toma la responsabilidad organizadora, sin embargo en poco tiempo se desentiende y Milla reconsidera la propuesta. (Jannello, "Boom" 79-105)

${ }^{54}$ John Hunt era secretario general del Congreso. Para un detalle preciso del organigrama del CLC, cfr.: Stonor Saunders, Frances, Who Paid the Piper? The CIA and the Cultural Cold War. Granta, Londres, 1999, 544 p.; y Scott-Smith, Giles, The Politics of Apolitical Culture: The Congress for Cultural Freedom and the Political Economy of American Hegemony 1945-1955. Routledge, Londres, 2002, $256 \mathrm{p}$.
} 
y legitimidad a las actividades que impulsaba el CLC ${ }^{55}$. Esta red de hecho había sido constituida en los años '50 con publicaciones preexistentes, como la revista Sur de Argentina o Humanismo en México, a las que las asociaciones latinoamericanas agregaron nuevos títulos como Cultura y Libertad de Chile, la mexicana Examen o la uruguaya Continente. Creadas ad hoc, estas publicaciones nunca alcanzaron gran repercusión. (Jannello, "Intelectuales" 79-105)

La propuesta entonces consiste en estimular proyectos revisteriles con trayectoria propia y sumarlos a estas redes que Mercier planea revitalizar. Si Sur fue una buena estrategia en la década previa, ahora "la revue de Victoria Ocampo... est considérée comme l'organe d'une génération vieillie et dépassée" 56 . Pero Número (que había sido inspirada en Sur) está constituida por un grupo que, podría decirse, sucede a la generación de los intelectuales de la revista porteña. Y sobre todo, quien hace posible su reaparición es Benito Milla, "qui a été le promoteur de l'édition en Uruguay... Il serait sans doute des plus utile de l'entretenir de nos propres projets sur le plan de l'édition, tant en Europe qu'en Amerique Latine"57. Mercier Vega va a proponer la compra de un cierto número de ejemplares por parte del CLC que ayudarán a subvencionar a Número. A cambio tiene la posibilidad de proponerles al editor y al redactor en jefe un cierto número de artículos sobre aspectos internacionales ${ }^{58}$.

Con el mismo estilo de revista-libro de los años 50, Número va a buscar "no sólo continuar la obra emprendida en su primera época, sino ampliarla hasta abarcar en forma más completa una realidad contemporánea" (Número 1, 2da. época, 3-4), pero más pronto que tarde esa realidad minará su comité de redacción con diferencias producidas en las posiciones tomadas por cada uno de sus miembros

${ }^{55}$ Carta de Louis Mercier Vega a John Hunt, Montevideo, 29 ag. 1963. Universidad de Chicago, Fondo IACF, S. II, B. 236.

${ }^{56}$ Ibíd.

${ }^{57}$ Carta de Mercier Vega a John Hunt, Montevideo, 7 ag. 1963. Universidad de Chicago, Fondo IACF, S. II, B. 236.

${ }^{58}$ El CLC adquiría 20 suscripciones anuales que no debían superar en total los cien dólares. Estas copias se enviaban al Secretariado en París, a los editores de Cuadernos, a los comités latinoamericanos, y a los escritores o críticos literarios miembros de los comités. Carta de L. Mercier Vega a J. Hunt, Montevideo, 19 feb. 1963. Universidad de Chicago, Fondo IACF, S. II, B. 236. 
CATEDRAL TOMADA: Revista de crítica literaria latinoamericana / Journal of Latin American Literary Criticism Benito Milla: un Ulises desgraciado en el Río de la Plata. De Cuadernos Internacionales a Mundo Nuevo, del socialismo libertario al humanismo antibelicista

respecto a la Revolución cubana. Solo aparecerán tres ejemplares entre abril de 1963 y mayo de 1964. (Jannello 115-133)

En septiembre de 1963 Benito Milla viaja a Europa y participa como jurado para el Gran Premio Internacional de Poesía Knokke-le-Zoute que obtiene Octavio Paz gracias a "aux efforts de nous ami" ${ }^{59}$. A su regreso va a ofrecer que Número se convierta en la revista orgánica del Centro Uruguayo (CUPC) que en unos meses abrirá sus puertas al público. El grupo editor se divide en la tensión de aceptar o rechazar la oferta, lo que sella el fin de uno de los emprendimientos más importantes de la cultura uruguaya. La siguiente propuesta de Benito Milla, continuadora de las experiencias de Deslinde y Letras 62, será en el marco del Instituto Latinoamericano de Relaciones Internacionales (ILARI), institución que proseguirá la gestión del Departamento Latinoamericano del CLC a partir de 1965.

\section{Los Temas en cuestión}

Sin duda, una de las omisiones más injustas dentro del campo revisteril latinoamericano es la que ocluyó a la revista Temas (1965-1968). Nacida en el contexto político de la Guerra Fría, Temas dialogó con la cultura internacional con colaboradores como Hans Magnus Enzensberger, Octavio Paz, Emir Rodríguez Monegal, Luce Fabbri, Susan Sontag, Arnold Toynbee, Jacques Carat, Augusto Roa Bastos, João Guimaraes Rosa, Aldo Solari, Jean Bloch-Michel, Domingo Rivarola, Alberto Moravia, Alain Robbe-Grillet o los jóvenes Fernando Aínsa, Alejandra Pizarnik, Mario Benedetti, Mario Vargas Llosa, o Umberto Eco, entre otros, y abordó temas variados que incluían literatura latinoamericana de autores consagrados y nuevas promociones, cuestiones sociológicas y reproducción de artículos de las otras revistas y autores internacionales. Sus números, de entre 60 y

\footnotetext{
59 Según el relato de Mercier Vega, Milla logró inclinar la votación a favor de Octavio Paz convenciendo a los jurados. Carta de Luis Mercier Vega a John Hunt, Santiago de Chile, 26 sept. 1963. Universidad de Chicago, Fondo IACF, S. II, B. 236.
} 
65 páginas cada uno, tenían un diseño moderno que pronto será imitado por la renombrada revista Mundo Nuevo de Emir Rodríguez Monegal, con la que compartió no solo vínculos institucionales e ideas, sino verdaderos lazos de amistad entre los directores. (Jannello, “Boom” 115-133)

Temas se lanza como expresión renovadora y aggiornada, luego de la desaparición de la anacrónica Cuadernos, con la intención primera de contrarrestar la vertiginosa expansión que había logrado en América Latina la Revolución cubana y su expresión cultural más exitosa: la Casa de las Américas (Ibíd.).

Editada por Alfa, pero órgano del CUPC, en su primer editorial declara que busca instalar un espacio donde "dialogar y confrontar supone reconocer implícitamente la presencia de los otros, no como enemigos sino como interlocutores" ("Diálogo" 2-3 [resaltado del original]), y aspira a "contribuir a la expresión de las preocupaciones culturales en el ámbito sudamericano" ("Propósito" 2), haciendo una clara alusión a la conflictiva polarización que había provocado la Guerra Fría en el ámbito de la cultura después de la Revolución cubana.

El panorama del lanzamiento de Temas no es muy favorable. En abril-mayo de 1965, cuando es lanzada, ocurre la invasión a Santo Domingo y se ve obligada en sus páginas a hacer frente a los hechos con una severa crítica que la coloque a una distancia prudente de los Estados Unidos y le asegure subsistencia. El segundo ejemplar se abre con un editorial crítico: “[...] los hechos en curso... han puesto de relieve, en primer lugar, la reavivada vocación del Departamento de Estado por las prácticas intervencionistas... por decisión unilateral y contra la voluntad del pueblo dominicano [...]" (“América" 2).

Y tan solo un par de meses más tarde, en junio de 1965, estallan las denuncias de intervencionismo estadounidense a través del Plan Camelot en el que se ve involucrada la FLACSO, institución que mantiene vínculos con el CLC y es financiada, al igual que este, por la Fundación Ford. Solo el prestigio del editor y de la red de sociabilidad construida en los años previos que fungen de garantía, y gracias a la aceitada cadena de distribución de Alfa, Milla logrará atenuar el estigma 
de su financiación y pertenencia, consiguiendo editar 16 números en 15 entregas que van a reunir no solo prestigiosas plumas, sino que funcionará, al igual que Deslinde y Letras 62 como plataforma de lanzamiento de jóvenes talentos que pronto saldrán a la luz en el escenario del Boom latinoamericano.

La opinión que busca conquistar Temas es la de la izquierda no castrista, aquella que por un lado huye de las derechas, y por otro necesita reafirmarse como izquierda ante una radicalización que polariza y exige definiciones. En su primer número, un artículo del joven Hiber Conteris analiza la politización de los intelectuales, aunque reconoce las presiones que se ciernen sobre este sector (“Compromiso" 19-21). La revista busca además distinguirse de la prensa diaria, a la que considera demasiado politizada, y ubicarse en una franja crítica. Milla ha ampliado el universo de sus colaboradores que ahora son, por un lado, distinguidos profesores de la universidad, sociólogos, historiadores o reconocidos escritores; por otro, jóvenes promesas. Publica, además de artículos de crítica cultural o social, crítica literaria, narrativa y poesía latinoamericana. Temas se convierte en este sentido en antecedente directo de Mundo Nuevo más allá de otros referentes como $S_{u r}{ }^{60}$. Es la primera en Uruguay en recoger a escritores como Guimarães Rosa, Augusto Roa Bastos o Mario Vargas Llosa -muy pronto faros del Boom literario-, aunque tampoco faltan grandes plumas como las de Octavio Paz, Stephen Spender, Gunter Grass o Alain Robbe-Grillet. Por último, Temas reproduce (aunque en una proporción mínima) artículos y debates de otras publicaciones de la red del CLC que toma como referentes, como Encounters o Preuves.

A pesar de la línea de diálogo que intenta fomentar la revista y de su declaración explícita de que "Su posición ante aspectos y problemas de actualidad está dada por sus editoriales", aparecen solo cinco de ellos entre el primer y el sexto número: el primero ("Propósito" 2), para presentar la revista; el segundo dedicado a criticar Santo Domingo ("América" 2); el tercero ("Diálogo" 2-3) reafirma la línea de diálogo que los anima, su posición frente a la lucha armada ("aspiramos a

${ }^{60}$ La revista porteña de Victoria Ocampo se encontraba en completo declive en esta década. 
contribuir [...] a liquidar uno de los estigmas más inhibitorios en la vida intelectual: el terrorismo como recurso de predominio"), su condición de "tribuna independiente" y su indeclinable vocación tercerista; el cuarto ("Moral” 2), donde ante la sentencia de los escritores soviéticos Siniavsky y Daniel, la revista se define socialista, aunque sin comulgar con el comunismo soviético; y el quinto ([Editorial] 2) en su primer aniversario (y en las vísperas de la aparición del primer número de Mundo Nuevo) donde se enuncia "libertaria", adherente a la "apertura cultural", la “desmilitarización ideológica” y a favor de la libertad.

En una América Latina polarizada, la apuesta de Temas es la de su director. En palabras de uno de sus colaboradores, Fernando Ainsa, Milla había traído una "terminología nueva -alteridad y otredad- puesta al servicio de un imposible idealismo... hablaba de 'los marxismos', del pluralismo cultural..." (Canon 101102). Efectivamente, Temas se preocupa por sostener un diálogo multidireccional que explora el problema del compromiso intelectual, el enfrentamiento entre los bloques o las derivas del marxismo; pero que también se preocupa por temas emergentes como los nuevos medios, la industria cultural o el erotismo en la literatura, además de darle voz, como ya he señalado, a jóvenes narradores y poetas.

Luego de las denuncias realizadas por la relación entre el CLC y la CIA, que comienzan a mediados de 1966 y se confirman hacia mediados de $1967^{61}$, Temas evitará pronunciarse, excepto por una breve nota en su número 10/11 (eneroabril 1967) en la que critica el dirigismo y la intervención en la cultura: "A los atentados contra la cultura perpetrados por el Estado soviético en las personas de Siniavski y Daniel se suma ahora éste de un organismo oficial norteamericano que [...] recurre al fraude y la corrupción". Se refiere a "la forma en que la CIA ha tratado de infiltrar a las organizaciones estudiantiles y a otras dedicadas a la investigación cultural y científica" ("Estado" 68-69).

${ }^{61}$ La primera denuncia sobre estos vínculos fue realizada por la revista Ramparts, secundada por el New York Times. Entre 1966 y 1967 fue el semanario Marcha, en su suplemento cultural dirigido en esos años por Ángel Rama, el encargado de difundirla. Luego de un proceso llevado a cabo en los EEUU, se comprobó que la CIA desviaba fondos del Plan Marshall a diversas fundaciones filantrópicas que luego los derivaban al CLC. Cfr.: Mudrovcic, María Eugenia. Mundo Nuevo. Cultura y Guerra Fría en la década del 60. Rosario: Viterbo, 1997. 
El escándalo va a teñir el esfuerzo realizado desde el CUPC, así como desde Temas, Mundo Nuevo y Aportes, las tres publicaciones que más circulaban de la red del desprestigiado CLC, asociándo estas producciones culturales a tareas de inteligencia e intervencionismo de los Estados Unidos. A pesar de ello, Benito Milla confiaba en el "trabajo constructivo de promoción cultural en el que estábamos embarcados" y en carta a Luis Mercier Vega solicitó que "los conductores mismos de la organización [...] establezcan, al más alto nivel, la realidad de las responsabilidades incurridas, única forma de saber si moralmente se está en condiciones de continuar trabajando"62. Ante la inevitable confirmación de la veracidad de las denuncias, finalmente lanzó una circular pública de aclaración desde el CUPC:

Ni el ILARI, ni de éste el Centro Uruguayo, recibieron jamás orientaciones susceptibles de definir sus actividades, ni decidir las personas que debían llevarlas a cabo o colaborar en las mismas... Hemos sido los únicos y libres responsables de cuanto se hizo en el plano nacional y estamos firmemente convencidos de habernos inspirado única y exclusivamente en los intereses superiores del diálogo entre las personas y de la libertad para toda expresión de la cultura. Este diálogo, en el plano nacional como en el internacional, nunca pudo servir los espúreos o tenebrosos designios de ningún gobierno, primero por la irrevocable conciencia independiente que nos anima, y segundo por la naturaleza eminentemente pública y abierta de nuestras tareas. ${ }^{63}$

Con estas palabras cerraba la sede uruguaya. Milla vive en un dejà vu permanente; resulta paradójico que se encontrara en esos años en la posición que él

\footnotetext{
62 Carta de Benito Milla a Luis Mercier Vega, 2 de marzo de 1967. Disponible en Fondo Luis Mercier Vega, CIRA.

${ }^{63}$ El texto se lanzó en forma de Circular y estaba firmado por Benito Milla, Hugo García Robles y Leonardo Milla.
} 
mismo criticara en los '50 a Bertrand Russell, cuando el filósofo británico ha realizado en los '60 un giro crítico con los Estados Unidos que lo lleva a crear el Tribunal Internacional sobre Crímenes de Guerra. La decepción lo retrotraerá en lo sucesivo nuevamente a su pensamiento libertario, que va a proyectar en la dirección de editorial Monte Ávila en los años que continúan.

Aun con todo, Temas salió un año más, hasta su número 16 (abril-junio 1968), cuando sin mediar mensaje alguno a sus lectores, se discontinúa, probablemente a razón de la emigración definitiva de Milla a Caracas, donde desde 1967 se dedica al exitoso proyecto editorial de Monte Ávila en el que va a continuar en su empeño por debatir el problema del escritor latinoamericano, concentrado, como en Uruguay, en "las preocupaciones literarias, sociales, políticas e historiográficas" (Milla, "Nueva promoción” 83-87).

\section{A modo de conclusiones}

El salto magnífico que dio la producción editorial y literaria uruguaya entre 1955 y 1965 estimuló, entre otras cosas, la renovación del canon. Existe un proceso y un periplo que acompañan la legitimación y consagración de los escritores y sus ideas. Los más jóvenes se insertan en redes de sociabilidad ya establecidas, construyen grupos, hegemonizan con la fuerza de su generación una época, buscan sus gestores culturales, exponen sus textos en espacios de consagración (como la sección cultural del semanario Marcha) o crean nuevos (como Número), la mayoría de las veces circulan en estas dos esferas. Luego llegará el libro, que no será el último escalón, sino uno más en un circuito más extenso que incluye la crítica, entrevistas para difusión, conferencias...

La figura del "gestor cultural" está en medio de cada una de estas instancias, la definición es lábil, escurridiza y compleja. Benito Milla es un administrador de cultura, aparece en cada una de estas faces: tiene ideas y busca difundirlas, escribe, pero no es suficiente; crea un espacio de sociabilidad primero 
en su puesto de libros, luego en la librería. Lee desenfrenadamente, edita revistas para expandir su mundo y cobijar esas ideas, luego libros, libros que presenta en su librería y en su centro cultural, motoriza la primera Feria del libro y el grabado, escribe crítica, dialoga, debate. Desde su arribo a Montevideo, Benito Milla entiende que su participación en el mundo cultural es casi un imperativo militante. Sus publicaciones deben entenderse insertas en el conjunto de lo que el editor catalán entiende por militancia cultural.

Supo captar con habilidad las necesidades planteadas por el contexto y lanzó dos publicaciones, Deslinde y Letras 62, que se constituyeron en un eslabón necesario en la producción crítica de la Generación del 45, proporcionando un espacio para su difusión, a la vez que estimuló con sus proyectos editoriales un universo más amplio. Tal como señalara Fernando Aínsa, uno de sus colaboradores, uno de sus méritos fue el de haber "promovido y potenciado a creadores y críticos uruguayos", pero también Milla adivinó "la mutación ideológica” que sobrevendría en esos años, hablando de los marxismos ya a fines de los '50, "lo que parecía una herejía para los marxistas ortodoxos uruguayos" (Aínsa, "Revista" 259-268).

Sus expectativas intelectuales pueden rastrearse en este hilo que reúne todas sus publicaciones: desde Cuadernos Internacionales a Temas, reconstruido aquí. Estas inquietudes además lo condujeron en un mar de ideas desde el anarquismo radical en el que se había formado en los años de la Guerra Civil a un humanismo libertario (que inevitablemente queda atrapado en las redes de la Guerra Fría), defensor de la democracia y respetuoso de las libertades, pero que no abandonó en ningún momento las cualidades de la utopía. 


\section{Bibliografía}

\section{Fondos de archivo}

Centro de Estudios Migratorios Latinoamericanos, Buenos Aires.

Centro de Documentación e Investigación de la Cultura de Izquierdas, Buenos Aires.

Emir Rodríguez Monegal Papers, Rare Books and Special Collections, Biblioteca de la Universidad de Princeton.

Internacional Association for Cultural Freedom, Joseph Regenstein Library, Universidad de Chicago.

Fonds Louis Mercier Vega, Centre international de recherches sur l'anarchisme, Lausana, Suiza.

\section{Revistas consultadas}

Capítulo Oriental. La historia de la literatura uruguaya, Montevideo (1968).

Clinamen. Revista bimestral. Montevideo (1947-1948).

Cuadernos Internacionales. Montevideo (1951-1952).

Deslinde. Montevideo, (1956-1961).

El Frente. Boletín de guerra de la Columna Durruti (1936-1939)

La Protesta. Buenos Aires (1949-1955).

Letras 62, Montevideo, (1962).

Marcha, Montevideo (1950-1965).

Número. Montevideo (1949-1964).

Solidaridad Obrera. Barcelona (1938).

\section{Libros y artículos}

Aínsa, Fernando. "Benito Milla: los puentes de la cultura". Del canon a la periferia: encuentros y transgresiones en la literatura uruguaya. Montevideo: Trilce, 2001, 101-102. 
. "La revista Temas: una propuesta humanista en los años sesenta",

Monteagudo, $3^{\mathrm{a}}$. época, 22 (2017), 259-268.

“América”. Temas, n 2, jun.-jul. 1965, p. 2.

Axelos, Kostas. El pensamiento planetario. Monte Ávila, Caracas, 1969.

Benedetti, Mario. "La literatura como catapulta". Letras 62, n² 2, dic. 1962, pp. 1, 4-5.

Bixen, Carina y Barros-Lemez, Álvaro, Ángel Rama. Cronología y bibliografía. Montevideo: Arca, 1986.

Circular del Centro Uruguayo de Promoción Cultural. Montevideo, marzo 1967. Fonds Louis Mercier Vega, Centre international de recherches sur l'anarchisme, Lausana, Suiza.

Clementi, Hebe (coord.), Inmigración española en la Argentina (Seminario 1990), Oficina cultural de la Embajada de España, Buenos Aires, 1991.

“Colaboradores de Deslinde”. Deslinde, n 10/11, mar. 1959, p. 25.

Conteris, Hiber. "El compromiso del escritor latinoamericano". Temas $\mathrm{n}^{\circ}$ 1, abr.may. 1965, pp. 19-21.

. "Entrevista a Hiber Conteris". Alejandra Torres Torres. Lectura y sociedad en los sesenta: a propósito de Alfa y Arca. Montevideo: Yagurú, 2012, pp. 183-186.

Cruz Arjona, C. "El falso dilema EEUU o Rusia". Cuadernos Internacionales, $\mathrm{n}^{\circ}$ 3, jul.-sept. 1951, pp. 163-166.

“Cuadernos Internacionales" [Índice]. AméricaLee. El portal de revistas latinoamericanas del CeDInCI. Web. 15 may. $2018<$ http://americalee.cedinci.org/portfolio-items/cuadernos-internacionales/>

“Deslinde. Literatura. Artes" [Índice]. AméricaLee. El portal de revistas latinoamericanas del CeDInCI. Web. 25 may. $2018<$ http://americalee.cedinci.org/portfolio-items/deslinde-literatura-arte/> “Deslinde”. Deslinde. n 1, ag. 1956, p. 1.

Espeche, Ximena. La paradoja uruguaya. Intelectuales, latinoamericanismo y nación a mediados de siglo XX. Bernal: UNQUI, 2016. 
"Estado y cultura". Temas, n 10/11, ene.-abr. 1967, pp. 68-69.

Di Maggio, Nelson, “La actividad plástica en Montevideo”. Deslinde, n 14/15, oct. 1960 , p. 7

“Diálogo en libertad" [editorial]. Temas no 3, sept-oct 1965, pp. 2-3.

[Editorial]. Temas, ${ }^{\circ}$ 6, abr.-may. 1966, p. 2.

Fernández Moreno, César. “¿Qué es una revista literaria?”. Marcha, n 871, 19 jul. 1957, p. 7.

García Robles, Hugo. “Entrevista a Hugo García Robles”. Alejandra Torres Torres. Lectura y sociedad en los sesenta: a propósito de Alfa y Arca. Montevideo: Yaugurú, 2012, pp. 193-198.

Gilman, Claudia. Entre la pluma y el fusil. Debates y dilemas del escritor revolucionario en América Latina. Buenos Aires: Siglo XXI, 2003. . "Enredos y desenredos de Ángel Rama y Emir Rodríguez Monegal”. Nuevo texto crítico, vol. xxiv-xxv, $n^{\circ}$ 47/48 (2011/2012): 69-92.

Gómez, Gabriela, "Estrellas en 45” [Entrevista a Carlos Maggi]. La Diaria, 11/1/2013. Consultado en julio 2018, disponible en <https//:la diaria.com.uy/articulo/2013/1/estrellas-en-45/>

Grémion, Pierre, Intelligence de l'Anticommunisme. Le Congrès pour la liberté de la culture à Paris 1950-1970. Fayard, París, 1995, 645 p.

Grillo, Rosa María, “Deslinde y Temas: Benito Milla, del exilio a la integración”, en Manuel Aznar Soler (ed.), Las literaturas del exilio republicano de 1939. Actas del II Congreso Internacional (Bellaterra, 1999), vol. I, 219230.

“Han dicho de Deslinde". Deslinde, n 3 (marzo 1957), p. 18.

Jannello, Karina. “El Boom latinoamericano y la Guerra Fría cultural. Nuevas aportaciones a la gestación de la revista Mundo Nuevo", Ipotesi, vol. 17, $\mathrm{n}^{\circ} 2$ (2013): 115-133.

. "Los intelectuales de la Guerra Fría. Una cartografía latinoamericana (1952- 1962)". Políticas de la Memoria, 14 (2013-2014): 79-105.

“La realidad de América”. Deslinde, n 10/11 (marzo 1959), p. 2. 
CATEDRAL TOMADA: Revista de crítica literaria latinoamericana / Journal of Latin American Literary Criticism Benito Milla: un Ulises desgraciado en el Río de la Plata. De Cuadernos Internacionales a Mundo Nuevo, del socialismo libertario al humanismo antibelicista

Leibner, Gerardo (2011), Camaradas y compañeros. Una historia política y social de los comunistas en Uruguay, Trilce, Montevideo, 2011.

“Letras 62. Publicación bimestral de artes y letras" [Índice]. AméricaLee. El portal de revistas latinoamericanas del CeDInCI. Web. 2 jun. 2018 <http://americalee.cedinci.org/portfolio-items/letras-62/>

Maggi, Carlos. “Sociedad y literatura en el presente: el 'Boom' editorial”. Capítulo Oriental. La historia de la literatura uruguaya, $\mathrm{n}^{\circ}$ 3, 1968.

Maline, J. "Colectivismo libre en Palestina”. Cuadernos Internacionales, $\mathrm{n}^{\circ} 2$, abr.-jun. 1951, pp. 93-97.

Martínez García, Ana, “Cartas desde Uruguay: Ramón J. Sender y la difusión de su obra en los proyectos editoriales de Benito Milla”. Alazet, 22, n. 19 (2010): 209-223.

Martínez Moreno, Carlos. "Carlos Fuentes y los nuevos caminos de la novela americana". Letras 62, n 2, dic. 1962, p. 8.

Maya (h), Ernesto. "El hombre en la sociedad actual”. Deslinde, n 4, jun. 1957, pp. 11-12.

Milla, Benito. "La guerra y la política internacional". Cuadernos Internacionales, $\mathrm{n}^{\circ} 2$, abr.-jun. 1951, pp. 90-92. . [Prólogo]. Cañaveral junto al mar. Buenos Aires: Américalee, 1952, p. 7. . “Los intelectuales y la política”. Deslinde, n² 2, nov. 1956, p. 18. . "Sobre un fondo sombrío. El testimonio de la novela española".

Deslinde, $\mathrm{n}^{\circ}$ 10/11, mar. 1959, pp. 4-5.

. "La ciudad de los otros". Deslinde, n 14/15, oct. 1960, pp. 12-13.

. ¿Qué pasa con el libro uruguayo? Una campaña para valorizar autores

y libros nacionales”. Letras 62, n 2, dic. 1962, p. 2.

. "Theodor Adorno y la rehabilitación de la crítica cultural”. Letras 62, n 2, dic. 1962, pp. 1, 3.

. "Una nueva promoción de lectores". Emir Rodríguez Monegal. Mundo Nuevo, $\mathrm{n}^{\circ} 19$, ene. 1968 , pp. 83-87. 
“Moral y política". Temas, n 5, ene.-mar. 1966, p. 2.

Mudrovcic, María Eugenia, Mundo Nuevo. Cultura y Guerra Fría en la década del 60. Rosario: Beatriz Viterbo Editora, 1997.

Otero, Cristóbal J. “León Felipe”. Cuadernos Internacionales, $\mathrm{n}^{\circ}$ 1, ene.-mar. 1951, pp. 33-37.

Paoletti, Mario, El aguafiestas. La biografía de Mario Benedetti. Buenos Aires: Seix Barral, 1995.

"Propósito". Cuadernos Internacionales, Montevideo, n. 1, enero/marzo 1951, pp. 3-4.

"Propósito", Temas n¹, abr-may 1965, p. 2.

Prunier, André. “A propósito de una pretendida ciencia de la revolución”. Cuadernos Internacionales, $\mathrm{n}^{\circ} 2$, abr.-jun. 1951, pp. 70-72.

Rama, Ángel. “Generación va y generación viene”. Clinamen, 5 (mayo 1948): 5253. . “Accidente en los Apeninos". Deslinde, n 6, sept. 1957, pp. 10-13.

Rama, Ángel y otros, Más allá del Boom. Literatura y mercado. México: Marcha Editores, 1981.

Rodríguez Monegal, Emir. Literatura uruguaya del medio siglo. Montevideo: Alfa, 1966.

Rocca, Pablo, "De las revistas literarias y otros quehaceres (Diálogo con Idea Vilarino, Manuel A. Claps y Mario Benedetti)”. Jornal de Poesía, [ca. 2001]. Recuperado el 02/02/2013 de <http://www.jornaldepoesia.jor.br/bh9rocca.htm> . Revistas culturales del Río de la Plata. Diálogos y tensiones (19451960), Universidad de la República, Montevideo, 2012.

Scott-Smith, Giles. The Politics of Apolitical Culture: The Congress for Cultural Freedom and the Political Economy of American Hegemony 1945-1955. Londres: Routledge, 2002.

"Steinbeck, Premio Nobel y revolucionario". Letras 62, n² 2, dic. 1962, p. 3. 
CATEDRAL Tomada: Revista de crítica literaria latinoamericana / Journal of Latin American Literary Criticism Benito Milla: un Ulises desgraciado en el Río de la Plata. De Cuadernos Internacionales a Mundo Nuevo, del socialismo libertario al humanismo antibelicista

Stonor Saunders, Frances, Who Paid the Piper? The CIA and the Cultural Cold

War. Londres: Granta, 1999.

Téllez-Solá, Antonio. "Sobre Ruta, CNT y Soli”. Historia libertaria, 6 (diciembre 1979): 39-40.

“Temas. Revista de cultura" [Índice]. AméricaLee. El portal de revistas latinoamericanas del CeDInCI. Web. 18 abr. $2017<$ http://americalee.cedinci.org/portfolio-items/temas/>

Torres Torres, Alejandra. Lectura y sociedad en los sesenta: a propósito de Alfa y Arca. Montevideo: Yaugurú, 2012.

Williams, Raymond. "The Bloomsbury faction". Problems in Materialism and Culture, Londres: Verso, 1980. 148-169.

Zea, Leopoldo. "Fenomenología de la derecha". Deslinde, n 12, sept. 1959, pp. $1,4-6$. 